\title{
Chromosomal microarray analysis as the first-tier test for the identification of pathogenic copy number variants in chromosome 9 pericentric regions and its challenge
}

\author{
Jia-Chi Wang* ${ }^{*}$ and Fatih Z. Boyar
}

\begin{abstract}
Chromosomal microarray analysis (CMA) has been recommended and practiced routinely in the large reference laboratories of U.S.A. as the first-tier test for the postnatal evaluation of individuals with intellectual disability, autism spectrum disorders, and/or multiple congenital anomalies. Using CMA as a diagnostic tool and without a routine setting of fluorescence in situ hybridization with labeled bacterial artificial chromosome probes (BAC-FISH) in the large reference laboratories becomes a challenge in the characterization of chromosome 9 pericentric region. This region has a very complex genomic structure and contains a variety of heterochromatic and euchromatic polymorphic variants. These variants were usually studied by G-banding, C-banding and BAC-FISH analysis. Chromosomal microarray analysis (CMA) was not recommended since it may lead to false positive results. Here, we presented a cohort of four cases, in which high-resolution CMA was used as the first-tier test or simultaneously with G-banding analysis on the proband to identify pathogenic copy number variants (CNVs) in the whole genome. CMA revealed large pathogenic CNVs from chromosome 9 in 3 cases which also revealed different G-banding patterns between the two chromosome 9 homologues. Although we demonstrated that high-resolution CMA played an important role in the identification of pathogenic copy number variants in chromosome 9 pericentric regions, the lack of BAC-FISH analysis or other useful tools renders significant challenges in the characterization of chromosome 9 pericentric regions.
\end{abstract}

Trial registration: None; it is not a clinical trial, and the cases were retrospectively collected and analyzed.

Keywords: Chromosome 9, Euchromatic variants, First-tier test, Heterochromatic variants, Interstitial deletion, Interstitial duplication, Pericentric inversion

\section{Headings}

CMA as the first-tier test for the identification of pathogenic $\mathrm{CNVs}$ in chromosome 9 pericentric regions and its challenge.

\section{Letter to the Editors}

Chromosomal microarray analysis (CMA) has been recommended as the first-tier test for the postnatal evaluation of individuals with intellectual disability, autism spectrum disorders, and/or multiple congenital anomalies

* Correspondence: jia-chi.j.wang@questdiagnostics.com

Cytogenetics Laboratory, Quest Diagnostics Nichols Institute, 33608 Ortega Highway, San Juan Capistrano, CA 92690, USA since 2010 [1, 2], and was later confirmed by other group [3]. This practice has become a standard for the large reference laboratories in U.S.A after the American College of Medical Genetics (ACMG) published the professional guidelines [4]. In these laboratories, CMA has largely replaced fluorescence in situ hybridization (FISH) analysis for the identification of pathogenic copy number variants (CNVs) across the whole genome.

Chromosome 9 pericentric regions have been known to contain a very complex genomic structure because of the presence of a huge amount of heterochromatin and large tracks of segmentally duplicated euchromatin $[5,6]$. The 
segmentally duplicated sequences predispose and mediate the generation of deletion, duplication, insertion, triplication and amplification variants within the pericentric regions of chromosome 9 [5, 7]. In a cohort of 334 carriers studied by using FISH analysis with different sets of labeled bacterial artificial chromosome (BAC) probes (BACFISH), 17 different types of heterochromatic variants of chromosome 9 have been identified [6], with pericentric inversions being the most frequent variant $(50 \%)$ followed by 9qh-variants $(24 \%)$ and 9ph-variants (11\%). Additionally, four different types of euchromatic variants have been detected: (1) 9p12 amplification variant [8, 9], (2) 9q12 insertion variant [5], (3) 9q21 deletion variant [5], and (4) 9q21 amplification variant [7]. Because of the presence of repetitive sequences, chromosomal microarray analysis (CMA) was not recommended to be utilized since it may lead to false positive results $[6,7]$.

For this reason, we retrospectively reviewed our postnatal database to search interesting cases with $\mathrm{CNVs}$ in chromosome 9. High-resolution CMA was either used as the first-tier test or simultaneously ordered with Gbanding analysis. For G-banding, peripheral blood was cultured for $72 \mathrm{~h}$ in RPMI-1640 medium. Metaphase chromosomes were analyzed using standard G-banding techniques. CMA was performed using genomic DNA extracted from uncultured whole blood on the oligo-SNP array (CytoScan $\mathrm{HD}^{\circ}$, Affymetrix). Hybridization, data extraction and analysis were performed as per manufacturer's protocols. The Affymetrix Chromosome Analysis Suite (ChAS) Software version 2.0 was used for data analysis, review and reporting. For chromosome 9, the probes from CytoScan $\mathrm{HD}^{\circ}$ covered the following genomic regions: 9p (chr9:192,129-40,784,142, 43,400,082-44,900,526) and 9q (chr9:66,837,485-141,025,328). Thresholds are set at
$>200 \mathrm{~kb}$ for gains, $>50 \mathrm{~kb}$ for losses for genome-wide region, and at $>100 \mathrm{~kb}$ for gains, $>20 \mathrm{~kb}$ for losses for cytogenetic relevant regions. Genomic coordinates are based upon genome build 37/hg19 (2009).

Patient 1 was a newborn girl who was referred to rule out a chromosomal anomaly. Using G-banding, it was initially reported as a common chromosome 9 normal pericentric inversion variant, 46,XX,inv(9)(p13q21.11), with a morphology similar to inv(9)(var2) in the previous report [6]. The second reviewer thought it was a large pericentric inversion, 46,XX, $\operatorname{inv}(9)(\mathrm{p} 13 \mathrm{q} 32)$ since the band 9q31 was missing (Fig. 1a, arrow) and instead inverted to 9p13 region (Fig. 1a, arrow head), and considered that it was not a variant. Further characterization of this large pericentric inversion by concurrent highresolution CMA revealed the presence of an interstitial deletion of $14 \mathrm{Mb}$ at 9q22.3-q32 (chr9:104,382,544118,273,644; hg19; Fig. 1b; the genes involved were listed in the Additional file 1: Table S1). The revised karyotype was $46, \mathrm{XX}, \operatorname{del}(9)(\mathrm{q} 22.3 \mathrm{q} 32) \operatorname{inv}(9)(\mathrm{p} 13 \mathrm{q} 21.11)$. It was concluded that two chromosomal rearrangements have occurred to the same chromosome 9: a polymorphic pericentric inversion and an interstitial deletion of $9 q 22.3-q 32$. It is actually very difficult to distinguish between the deletion of $9 \mathrm{q} 22-\mathrm{q} 32$ and $9 \mathrm{q} 32-\mathrm{q} 34$ without using molecular cytogenetic methods [10, 11]. Usually the patients with interstitial deletions involving $9 \mathrm{q} 22$ had a loss of the PTCH1 gene (chr9: 98,205,265-98,279,247), and thus revealed typical features of Gorlin syndrome [12-14]. However, since the deletion in this patient was distal to the PTCH1 gene, this newborn girl did not have Gorlin syndrome.

Patient 2 was a 2-year-old girl with developmental delay, lack of coordination, mixed receptive expressive a

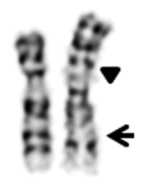

b

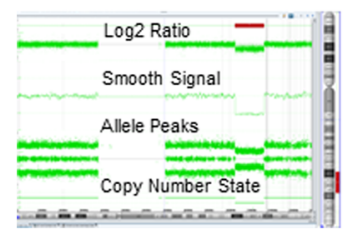

C

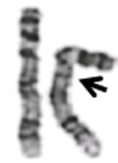

e
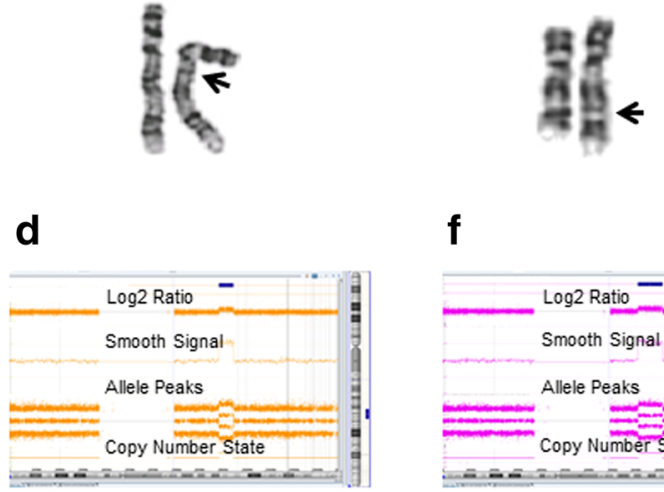

f

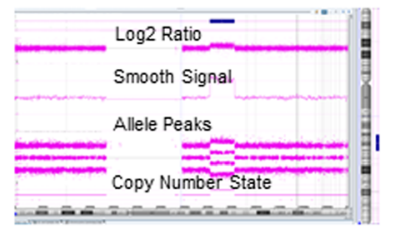

g

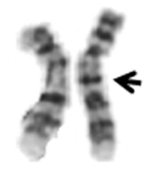

h

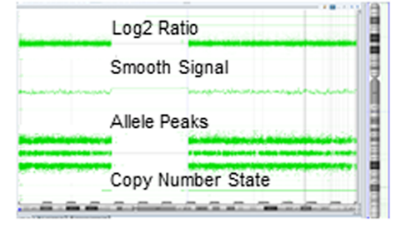

Fig. 1 a G-banding analysis of patient 1 revealed a pericentric inversion of chromosome 9; the missing band 9q31 (arrow) was initially considered to be inverted to 9p13 region (arrow head); b CMA identified a pathogenic interstitial deletion of 14 Mb at 9q22.3-q32 (chr9:104,382,544118,273,644; hg19); c G-banding analysis of patient 2 revealed an extra band at 9qh; d CMA identified a pathogenic gain of 6.3 Mb from 9q21.33q22.31 (chr9:90,1 18,500-96,395,801); e G-banding analysis of patient 3 revealed an extra band at the 9q22.1 region; $\mathbf{f}$ CMA identified a $10.4 \mathrm{Mb}$ pathogenic gain from 9q21.31-q22.2 (chr9:82,745,056-93,173,691); $\mathbf{g}$ G-banding analysis of patient 4 revealed an extra band at 9q12 region with a morphology similar to that of patient 2; $\mathbf{h}$ CMA did not reveal copy number changes, which ruled out the presence of pathogenic variants 
language disorder and convulsion. It was initially considered as a chromosome 9 euchromatic variant with an extra G-dark band within the proximal 9q heterochromatin region or it could be an insertion or duplication from 9q13-q21.1 (Fig. 1c, arrow). The C-banding was negative. This type of euchromatic variant has been reported in several cases $[5,15,16]$ and classified as one of the four major categories of euchromatic variant [7]. The high-resolution CAM that was simultaneously performed, however, showed a genomic gain of $6.3 \mathrm{Mb}$ from 9q21.33-q22.31 (chr9:90,118,500-96,395,801; hg19; Fig. 1d; genes involved listed in the Additional file 1: Table S1). This case was an excellent example of how CMA analysis showed that an extra G-dark band in proximal 9q was a pathogenic duplication of proximal 9q rather than a euchromatic variant. This gain did not include the PTCH1 gene (located at chr9: 98,205,265-98,279,247) and, thus the phenotype was different from the previously reported familial cases with 9q22.3 microduplication spanning PTCH1 [17], and without microcephaly or holoprosencephaly that were often seen in patients with gain of PTCH1 [18].

Patient 3 was a 24-year-old woman referred to rule out a chromosomal disorder with reported family history of a chromosome 9 abnormality. G-banding analysis considered it was an insertion of an extra band to the 9q22 region (Fig. 1e). CMA revealed it was a duplication of 10.4 Mb from 9q21.31-q22.2 (chr9:82,745,056-93,173,691; Fig. 1f; genes involved listed in the Additional file 1: Table S1). Duplication of $9 \mathrm{q} 21.2-\mathrm{q} 22.3$ was reported in a 2year-old female with growth and motor retardation and in her aunt without apparent phenotypic anomalies [19], and a more distal duplication of 9q22.31-q22.32 was associated with congenital diaphragmatic hernia [20]. Our patient was not known to have these anomalies.

Patient 4 was a 10 -year-old boy with failure to thrive and cognitive deficits. G-banding analysis revealed an extra band at 9q12 region (Fig. 1g), and C-banding was positive (Additional file 2: Figure S1). CMA did not reveal copy number variants (Fig. 1h) since the probes from the CMA apparently did not cover the repetitive sequences. The G-positive and C-positive extra band in this case was concluded as a rare heterochromatic variant [6], instead of a G-positive and C-negative euchromatic variant [7].

The four cases described here demonstrate how CMA characterize the chromosome 9 pericentric regions along with G-banding and/or C-banding without access to BAC-FISH analysis. Patient 1 was a very rare case with the presence of an interstitial deletion which coexisted with a polymorphic pericentric inversion. Patient 2 was an excellent example of how CMA differentiated a pathogenic gain from a heterochromatic variant as observed in patient 4 . In patient 3 , CMA revealed it was a likely pathogenic duplication although previous report showed a reduced penetrance in one family study [19].

Although we demonstrated that high-resolution CMA played an important role in the identification of pathogenic copy number variants in chromosome 9 pericentric regions, the lack of BAC-FISH analysis as a routine setting in the large reference laboratory renders significant challenges in further characterization of chromosome 9 variants. The major advantage of using CMA as the first-tier test is to detect pathogenic CNVs across the whole genome including chromosome 9. However, when a huge amount of heterochromatin and large tracks of segmentally duplicated euchromatin are present in chromosome 9 pericentric regions, CMA was unable to differentiate tandem, inverted and insertional duplication, or to confirm pericentric inversion. Our cohort supported using CMA as first-tier test when chromosomal disorders were indicated to rule out the presence of pathogenic copy number variants, and using BACFISH analysis to further evaluate heterochromatic and euchromatic variants of chromosome 9 .

\section{Additional files}

Additional file 1: Table S1. List of genes that are involved in the CNVs of case 1-3. (DOC $32 \mathrm{~kb}$ )

Additional file 2: Figure S1. The extra G-positive band was most likely C-positive by C-banding analysis (arrow) in one chromosome 9 homologue, which indicated that the extra band was heterochromatin in origin. The other chromosome 9 homologue also showed a large amount of heterochromatin (arrow head). The C-banding result was not $100 \%$ conclusive, and thus using BAC-FISH with proper probes will be able to confirm this result. (JPG $28 \mathrm{~kb}$ )

\section{Abbreviations}

BAC, bacterial artificial chromosome; CMA, chromosomal microarray analysis; $\mathrm{FISH}$, fluorescence in situ hybridization

\section{Acknowledgements}

The authors acknowledge that Andrew Hellman and Jeff Radcliff provided valuable assistance in manuscript revisions.

Funding

Not applicable.

\section{Availability of data and materials}

The raw data and materials used for this study have been de-identified and were freely available to any scientist wishing to use them without breaching participant confidentiality.

Authors' contributions

JCW- reviewing, analysis and interpretation of the data, drafting and revising the article, final approval of the version to be published. FZB - interpretation of data. Both authors read and approved the final manuscript.

\section{Competing interests}

The authors declare that they have no competing interests.

\section{Ethics approval and consent to participate}

This manuscript is a retrospective case report that does not require ethics committee approval at our institution. Consent was considered not required because the cases reported here were anonymous and de-identified. 
Received: 12 July 2016 Accepted: 28 July 2016

Published online: 10 August 2016

\section{References}

1. Manning M, Hudgins L. Array-based technology and recommendations for utilization in medical genetics practice for detection of chromosomal abnormalities. Genet Med. 2010;12:742-5.

2. Miller DT, Adam MP, Aradhya S, Biesecker LG, Brothman AR, Carter NP, Church DM, Crolla JA, Eichler EE, Epstein CJ, Faucett WA, Feuk L, Friedman JM, Hamosh A, Jackson L, Kaminsky EB, Kok K, Krantz ID, Kuhn RM, Lee C, Ostell JM, Rosenberg C, Scherer SW, Spinner NB, Stavropoulos DJ, Tepperberg JH, Thorland EC, Vermeesch JR, Waggoner DJ, Watson MS, Martin CL, Ledbetter DH. Consensus statement: chromosomal microarray is a first-tier clinical diagnostic test for individuals with developmental disabilities or congenital anomalies. Am J Hum Genet. 2010;86:749-64.

3. Battaglia A, Doccini V, Bernardini L, Novelli A, Loddo S, Capalbo A, Filippi T, Carey JC. Confirmation of chromosomal microarray as a first-tier clinical diagnostic test for individuals with developmental delay, intellectual disability, autism spectrum disorders and dysmorphic features. Eur J Paediatr Neurol. 2013;17:589-99.

4. Kearney HM, Thorland EC, Brown KK, Quintero-Rivera F, South ST. American College of Medical Genetics standards and guidelines for interpretation and reporting of postnatal constitutional copy number variants. Genet Med. 2011;13:680-5

5. Willatt LR, Barber JC, Clarkson A, Simonic I, Raymond FL, Docherty Z, Ogilvie CM. Novel deletion variants of 9q13-q21.12 and classical euchromatic variants of $9 q 12 / q h$ involve deletion, duplication and triplication of large tracts of segmentally duplicated pericentromeric euchromatin. Eur J Hum Genet. 2007;15:45-52.

6. Kosyakova N, Grigorian A, Liehr T, Manvelyan M, Simonyan I, Mkrtchyan H, Aroutiounian R, Polityko AD, Kulpanovich Al, Egorova T, Jaroshevich E, Frolova A, Shorokh N, Naumchik IV, Volleth M, Schreyer I, Nelle H, Stumm M, Wegner RD, Reising-Ackermann G, Merkas M, Brecevic L, Martin T, Rodriguez L, Bhatt S, Ziegler M, Kreskowski K, Weise A, Sazci A, Vorsanova S, Cioffi Mde B, Ergul E. Heteromorphic variants of chromosome 9. Mol Cytogenet. 2013;6:14.

7. Joseph-George AM, He Y, Marshall CR, Wong RC, MacDonald JR, Fahey CA, Chitayat D, Chun K, Ryan G, Summers AM, Winsor EJ, Scherer SW. Euchromatic 9q13-q21 duplication variants are tandem segmental amplifications of sequence reciprocal to 9q13-q21 deletions. J Med Genet. 2011;48:317-22.

8. Di Giacomo MC, Cesarano C, Bukvic N, Manisali E, Guanti G, Susca F. Duplication of 9 p 11.2-p13.1: a benign cytogenetic variant. Prenat Diagn. 2004;24:619-22

9. Lecce R, Murdolo M, Gelli G, Steindl K, Coppola L, Romano A, Cupelli E, Neri $\mathrm{G}$, Zollino M. The euchromatic $9 p+$ polymorphism is a locus-specific amplification caused by repeated copies of a small DNA segment mapping within 9p12. Hum Genet. 2006;118:760-6.

10. Farrell SA, Siegel-Bartelt J, Teshima I. Patients with deletions of 9q22q34 do not define a syndrome: three case reports and a literature review. Clin Genet. 1991;40:207-14

11. Schinzel A. Catalogue of unbalanced chromosome aberrations in man. New York: Walter de Gruyter; 2001

12. Chen $C P$, Lin SP, Wang TH, Chen YJ, Chen M, Wang W. Perinatal findings and molecular cytogenetic analyses of de novo interstitial deletion of 9q (9q22.3> q31.3) associated with Gorlin syndrome. Prenat Diagn. 2006;26:725-9.

13. Midro AT, Panasiuk B, Tumer Z, Stankiewicz P, Silahtaroglu A, Lupski JR, Zemanova Z, Stasiewicz-Jarocka B, Hubert E, Tarasow E, Famulski W, ZadroznaTolwinska B, Wasilewska E, Kirchhoff M, Kalscheuer V, Michalova K, Tommerup N. Interstitial deletion 9q22.32-q33.2 associated with additional familial translocation t(9;17)(q34.11;p11.2) in a patient with Gorlin-Goltz syndrome and features of Nail-Patella syndrome. Am J Med Genet A. 2004;124A:179-91.

14. Boonen SE, Stahl D, Kreiborg S, Rosenberg T, Kalscheuer V, Larsen LA, Tommerup N, Brondum-Nielsen K, Tumer Z. Delineation of an interstitial 9q22 deletion in basal cell nevus syndrome. Am J Med Genet A. 2005;132A:324-8.

15. Barber JC, Rodrigues R, Maloney VK, Taborda F, do C Rodriguez M, Bateman MS. Another family with a euchromatic duplication variant of 9q13-q21.1 derived from segmentally duplicated pericentromeric euchromatin. Cytogenet Genome Res. 2013;141:64-9.

16. Madan K. An extra band in human 9qh + chromosomes. Hum Genet. 1978;43:259-64.
17. Izumi K, Hahn A, Christ L, Curtis C, Neilson DE. Familial 9q22.3 microduplication spanning PTCH1 causes short stature syndrome with mild intellectual disability and dysmorphic features. Am J Med Genet A. 2011;155A:1384-9.

18. Derwinska K, Smyk M, Cooper ML, Bader P, Cheung SW, Stankiewicz P. PTCH1 duplication in a family with microcephaly and mild developmental delay. Eur J Hum Genet. 2009;17:267-71.

19. Kajii T, Matsuura S, Murano I, Kuwano A. Inverted insertion (9)(q34.3q22. $3 q 21.2)$ and its recombination product: duplication 9q21.2q22.3. Jinrui idengaku zasshi. Jpn J Hum Genet. 1987;32:45-50.

20. Stark Z, Behrsin J, Burgess T, Ritchie A, Yeung A, Tan TY, Brown NJ, Savarirayan $\mathrm{R}$, Patel N. SNP microarray abnormalities in a cohort of 28 infants with congenital diaphragmatic hernia. Am J Med Genet A. 2015;167A:2319-26.

\section{Submit your next manuscript to BioMed Central and we will help you at every step:}

- We accept pre-submission inquiries

- Our selector tool helps you to find the most relevant journal

- We provide round the clock customer support

- Convenient online submission

- Thorough peer review

- Inclusion in PubMed and all major indexing services

- Maximum visibility for your research

Submit your manuscript at www.biomedcentral.com/submit
Biomed Central 